\title{
A Psychiatric Day Care Service in Zambia
}

\author{
By M. Dhadphale, University of Nairobi and S. P. Shaikh, Central Hospital, Ndola
}

Since independence in sub-Saharan Africa, decentralization of psychiatric services has been accepted as a policy, but it has resulted so far only in developing small units attached to the provincial hospitals. Because of the shortage of qualified psychiatrists, the latter are invariably staffed by locally trained psychiatric or sometimes general nurses. With one or two exceptions most of the mental hospitals were built in the colonial times and they often resemble penal institutions and are geared mainly to offering custodial care.

Except in Nigeria and Tanzania, there has been little progress in providing satisfactory day care for mental patients. In Nigeria, Lambo (1956) pioneered the village system connected to Aro day hospital, which was further developed by Asuni (1964). Lambo's patients returned to foster homes in nearby villages where a night nurse was on duty to attend to minor emergencies. He offered a full range of treatment facilities in the day hospital, and the patients spent several hours each day in occupational or recreational activities. In Tanzania, Swift (1969) established similar villages for convalescent mental patients before they were finally discharged to their homes.

The priorities in the third world health programme are different from those in developed countries. Psychiatric services get low priority, and very little money is allocated to starting new community-based services. In these circumstances, voluntary bodies such as Mental Health Associations play a key role in initiating a community project. Unlike governments, they often achieve quick success in their goals owing to readily available funds and absence of red tape (Carstairs, 1973). The authors of this article obtained funds and help in kind for their day hospital project from the local branch of the Mental Health Association. Kellam and Schiff (1968) have discussed the importance of local participation and financing as an essential factor leading to the success of such projects.

The relatives of mental patients tend to believe that once the patient is admitted to a psychiatric hospital he is likely to remain for a long time, if not for ever; consequently, they often fail to visit. Another contributing factor for this failure is lack of money for travel. As a result, the patient rapidly loses contact with his family. The situation of a married woman with young children is even more critical, as the longer she remains in hospital the more difficult it is for her to be rehabilitated back into the family. In such situations, the day hospital plays a valuable role. We were able to preserve all the marriages and families of our day patients. A woman spending nights at home is able to care for her children and even cook an evening meal for the family and send the children away to school in the morning.

Since jobs are scarce, efforts must be made to protect those of mental patients. This objective can be achieved by inviting the employer to come and discuss the patient's problems with staff; as a result, the employers come to look upon the patient as a sick man who can be taken back at work once discharged from day care. This important objective can be achieved by day care alone.

\section{Ndola day hospital}

The psychiatric services on the copperbelt of Zambia were well organized, with regular out-patients clinics being run at the major mining towns. The department of psychiatry was part of the modern Ndola Central Hospital, a multidisciplinary semi-teaching medical institution. The authors were able to open the day hospital, as a pilot project, in 1976. The local branch of the Mental Health Association equipped the hospital and provided the services of a qualified carpenter and money for buying further necessities.

Premises: The psychiatric department was located about $100 \mathrm{~m}$ from the main central hospital and was housed in a few old buildings. It had about 120 in-patients in 1976. The department received nearly 60 per cent of its patients from Ndola and nearby townships while the rest came from elsewhere.

Staff: A senior psychiatric nurse, a trained occupational therapist and four of the latter's assistants formed the nucleus of the day staff. The consultant psychiatrist or his deputy supervised the running of the project, and held weekly meetings with the staff to assess the progress of each patient. As all patients knew the staff while they were inpatients, good staff-patient relationships were established with ease. Invariably the patients enjoyed coming to and working at the day hospital.

Selection of patients: Twelve recently discharged patients who lived within the townships were assessed by the consultant and the day hospital staff for their suitability as day hospital patients. All of them had a home to return to at night, and a responsible relative to look after them while at home. Diagnoses included chronic schizophrenia, psychosocial problems, personality disorders, epilepsy with mental retardation, manic-depressive ilness and early dementia. There were seven men and five women in the age range of 19-54.

Transport: A minibus donated by a Hindu cultural organization to the Mental Health Association was used for transporting the patients.

Activities and treatment: Patients had breakfast and morning medication on arrival. They worked individually or, more frequently, in small groups. The programme for each patient was decided by the team consisting of the psychiatrist, the day hospital nurse and the occupational 
therapist. The patients worked until lunchtime. Facilities existed for carpentry, basket-making, toy-making, knitting, painting, woodwork, cooking and similar skills. A qualified carpenter was in attendance for supervising some of the patients. A few patients took part in gardening and grew maize as well as green vegetables in the 'farm' just outside the department. Twice a week, the patients cooked their own lunch and often tried a new preparation.

In the afternoons there were mainly recreational activities. These consisted of film shows, traditional dancing, group meetings, music and other entertainment programmes. Frequently the relatives joined the patients in discussion groups. A weekly assessment was made of every patient's mental state, social progress and occupational skill. Once a month the patients were taken out to visit the amusement park or nearby places of interest.

The adjoining department of psychiatry provided all the psychiatric treatment facilities. A patient who was on the verge of relapse could be offered immediate temporary transfer to the admission wards.

Whenever possible, the relatives were invited to join the group discussion and meet the nursing and occupational therapy staff and the social worker. The day hospital became so popular in the first three months that a waiting list had to be introduced.

\section{Concluding remarks}

Our day experience indicates that any present hospital or health centre in a developing country can offer day care services. It is not at all necessary to employ additional staff, buy expensive equipment or seek Government aid. The local voluntary organization will help once they are convinced about the project's advantages. At least for several years to come, the developing countries will have to look after a mixed psychiatric clientele and cannot separate special groups, such as neurotics or geriatrics, as day patients.

The health authorities should direct their planning, scarce skilled personnel and meagre financial resources to providing more day care facilities by involving the local communities and utilizing the existing health institutions. Lambo's (1956) remarks about day care, ' $\ldots$ that the community can have the opportunity of watching the gradual process of recovery of the patients, thereby changing their views on the alleged causation and course of mental illnesses perhaps by exhibiting more tolerance', were made 25 years ago but are still appropriate to our situation.

\section{Acknowledgement}

The authors thank the Director of Medical Services, Ministry of Health, Lusaka, Zambia, for his permission to publish this paper.

\section{REFERENCES}

AsuNI, T. (1964) Community development of mental health services in Nigeria. West African Medical Journal, 13, 151-4.

Carstarrs, G. M. (1973) Psychiatric problems of developing countries. British Journal of Psychiatry, 123, 271-7.

KELLAM, S. G. \& SCHIFF, S. K. (1968) An urban community mental health centre. In Mental Health and Urban Social Policy (eds. L. H. Duhl and R. L. Leopold), p 113. San Francisco: Jossey-Buss.

LAMBO, T. A. (1956) Neuropsychiatric observations in the Western region of Nigeria. British Medical Journal, pp 1388-94.

SwIFT, C. R. (1969) Villages for Convalescent Psychiatric Patients. Commonwealth Foundation, London, Occasional Papers, No. 4, pp 37-9.

\section{'Where Stands Psychiatry?'}

By G. P. S. Fernando, Consultant Psychiatrist, University of Otago, Wellington, New Zealand

Of recent years psychiatry has been assailed from many sides. Psychologists, political philosophers, social workers have had their say, but the most hurtful have been assaults from within the citadel itself, such as the forceful views expressed by R. D. Laing and Thomas Szasz. The essence of their argument is that mental disorder is not a disease nor an illness and should not therefore be the concern of doctors.

Psychiatrists have responded to these often bitter criticisms in various ways, ranging from utter disdain to attempts to justify and defend their positions (Ironside, 1977; Roth, 1973; Ellis, 1977).

However, turning over the pages of history, one cannot

-A brief article prepared in reply to 'Doctors and Counsellors: Collaboration or Conflict' (Bulletin, July 1980) and 'Multidisciplinary Teams: A Personal View' (Bulletin, June 1980). but be impressed by the fact that in ancient times it was philosophers such as Empedocles (5th century BC), Plato (427-347 BC) and Aristotle (384-322 BC), historians such as Plutarch (46-120 AD) and other non-medical authorities who have discoursed at length on mental illness. Later, during the European Middle Ages, theologians, both reformists and counter-reformists, believed that mental illness was a diseased condition of the soul and so needed to be purified by fire. But as always these were more enlightened times, too. Juan Luis Vives (1492-1540), philosopher, humanist and courtier of Catherine of Aragon, figures largely in Zilboorg's History of Medical Psychology, and of him Sir William Hamilton wrote: 'Vives' observations regarding mental disorder comprised in brief nearly all of principal moment ever said before or since'. In the 17th and 18th centuries, the Age 